\title{
ANALISIS TEKNIKAL UNTUK PREDIKSI PORTOFOLIO SAHAM YANG OPTIMAL DENGAN MENGGUNAKAN BAYESIAN NETWORK
}

\author{
Pristiwati Fitriani \\ STMIK Logika \\ Jl. K.L Yos Sudarso No. 374 C Medan \\ Email: pristiwati_fitriani@yahoo.co.id
}

\begin{abstract}
ABSTRAK- Pengambilan keputusan bagi investor untuk melakukan investasi pada saham selalu mempertimbangkan faktor perolehan dan risiko. Risiko diidentifikasikan dengan ketidakpastian. Bayesian Network adalah representasi grafis dari gabungan probabilitas fungsi distribusi yang lebih dari satu set variabel. Bayesian Network merupakan Diagram Asiklik Grafik (DAG) yang mendefinisikan faktorisasi distribusi probability bersama atas variabel yang diwakili oleh node dari DAG. Bayesian Network telah digunakan untuk data mining model grafis yang membuat hubungan probabilistik antara variabel interest, digunakan teknik statistik, model grafis memiliki beberapa keuntungan bagi pemodelan data. Bayesian Network dapat menyelesaikan masalah prediksi portofolio saham berdasarkan analisis teknikal untuk basis data yang bersifat statistik. Analisis pengujian dilakukan dengan 2 cara dengan Microsoft Visual Basic 6.0 dan Microsoft Excel. Indikator yang digunakan untuk analisis saham terdiri atas Simple Moving Average (SMA), Relative Strength Index (RSI) dan Bollinger Bands (BB). Dengan menerapkan metode Bayesian Network dapat menentukan portofolio saham yang optimal dapat mengetahui kapan sebaiknya melakukan transaksi jual dan beli saham.
\end{abstract}

Kata kunci : Bayesian Network, Saham, Portofolio, Pemodelan Data.

\section{PENDAHULUAN}

Pengambilan keputusan bagi investor untuk melakukan investasi pada saham selalu mempertimbangkan faktor perolehan dan resiko. Resiko diidentifikasikan dengan ketidakpastian. Keputusan investasi pada dasarnya menyangkut masalah pengelolaan dana pada suatu periode tertentu, di mana para investor mempunyai harapan untuk memperoleh pendapatan atau keuntungan dari dana yang diinvestasikan selama periode waktu tertentu.

Sebelum mengambil keputusan investasi baru, para investor perlu mengadakan analisa yang cermat. Keuntungan investasi sangat tergantung banyak hal, tapi hal yang utama adalah tergantung pada kemampuan atau strategi penanaman modal atau investor dalam membaca keadaan dan situasi pasar tidak menentu. Bila harga saham naik maka keuntungan yang dimiliki pemodal akan meningkat. Kenaikan harga saham dan permintaan yang tinggi merupakan daya tarik tersendiri bagi perusahaan untuk menerbitkan saham. Penanam modal untuk membeli saham berarti mereka membeli prospek suatu perusahaan.

Di dalam pembentukan protofolio saham, investor akan memilih mana portofolio saham yang tepat dari sekian banyak portofolio saham yang ada. Untuk dapat memilih portofolio saham yang tepat diperlukan analisa yang tepat dan cukup karena banyaknya analisa yang perlu dipertimbangkan dalam proses pemilihan portofolio saham, maka diperlukan sebuah sistem di mana dalam suatu komunitas yang saling berinteraksi, bernegosiasi dan berkoordinasi satu sama lain.

Menurut [1], Bayesian Network merupakan metode pendekatan untuk mengukur suatu yang mengandung ketidak-pastian yang diukur dengan probabilitas. Dengan menggunakan pendekatan probabilitas tingkat ketidakpastian dapat diukur secara matematis.

Bayesian Network telah digunakan untuk data mining model grafis yang membuat hubungan probabilistik antara variabel interest, digunakan teknik statistik, model grafis memiliki beberapa keuntungan bagi pemodelan data dan Bayesian Network dapat menyelesaikan masalah prediksi portofolio saham berdasarkan analisis teknikal untuk basis data yang bersifat statistik.

1.1 Rumusan Masalah

1. Bagaimana memanfaatkan metode Bayesian Network untuk memilih dan menentukan portofolio saham yang layak dan optimal.

2. Bagaimana motode Bayesian Network digunakan untuk melakukan prediksi atau peramalan terhadap sebuah portofolio saham apakah melakukan transaksi jual atau beli.

3. Bagaimana membuat aplikasi prediksi saham yang dapat digunakan investor dan user friendly.

\subsection{Batasan Masalah}

1. Dalam menyelesaikan masalah prediksi portofolio saham ini menggunakan metode Bayesian Network, dalam hal ini metode-metode yang mempengaruhi pembentukan prediksi portofolio saham dipandang pelaku ekonomi yang saling berinteraksi satu sama lain yang menghasilkan fenomena yang dilihat sebagai faktor agregasi dalam analisis yang dibangun

2. Hanya beberapa indikator teknikal modern yang digunakan untuk memberikan masukan kapan portofolio saham tersebut dijual dan kapan portofolio saham itu dibeli. 
3. Portofolio saham yang digunakan sebagai sampel dalam menyelesaikan hanya beberapa saham yang masuk dalam Bursa Efek Jakarta (BEJ).

4. Data yang dikumpul dari situs www.finance@yahoo.com. Data saham yang digunakan hanya harga penutup (close) dan periode waktu persatu hari.

5. Perangkat lunak yang dibangun sebagai hasil penerapan atau implementasi menggunakan metode Bayesian Network dan bahasa pemrograman Microsoft Visual Basic 6.0

\subsection{Tujuan Penelitian}

Tujuan dari penelitian ini adalah :

1. Menerapkan metode Bayesian Network untuk menentukan portofolio saham yang optimal untuk dipilih.

2. Mengetahui kapan sebaiknya melakukan transaksi jual dan beli

\subsection{Manfaat Penelitian}

1. Memberikan informasi dan pengetahuan tentang pembentukan portofolio yang optimal.

2. Sebagai bahan masukan bagi para investor dalam melakukan jual beli saham.

3. Dengan adanya analisis teknikal portofolio saham, diharapkan para pengguna atau investor dapat mengurangi tingkat resiko yang akan diperoleh.

\section{ISI PENILITIAN}

\subsection{Metode Penelitian}

Adapun kerangka kerja penelitian ini dapat digambarkan pada gambar berikut:

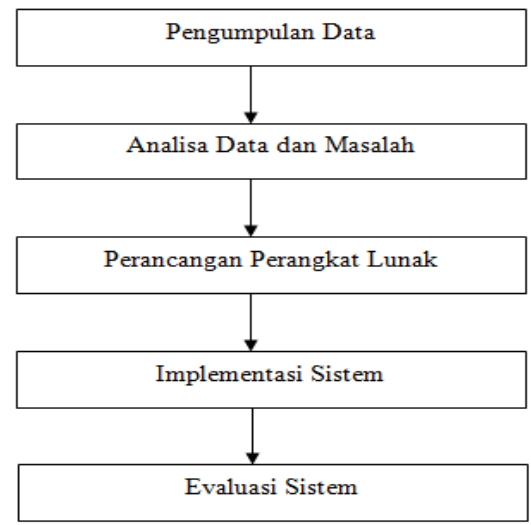

Gambar 1 Kerangka Kerja Penelitian

Menurut [2], Bayesian Network berasal dari teorema Bayes, teorema Bayes adalah sebuah pendekatan untuk sebuah ketidakpastian yang diukur dengan probabilitas. Teorema ini dikemukakan oleh Thomas Bayes dengan rumus dasar:

$$
P(B \mid A)=\frac{P(A B) P(B)}{P(A)}
$$

Menurut [4], Pada umumnya struktur Bayesian Network terdiri dari 2 bagian yaitu :

\section{Directed Acyclic Graph (DAG)}

DAG ini terdiri dari node dan busur-busur (arcs) yang menghubungkan antara node yang satu dengan node yang lain. Node pada Bayesian Network merepresentasikan variabel atau atribut. Sedangkan busur merepresentasikan relasi ketergantungan atau hubungan kausal antara dua node. Pada BN, node terdiri dari dua jenis, yaitu nodeclass dan node atribut. Nodeclass mewakili variabel class yang merupakan target klasifikasi pada dataset, sedangkan node atribut mewakili variabel-variabel selain variabel class. Apabila dua buah node dihubungkan oleh sebuah busur, maka kausal node akan menjadi parent node dari node yang lain.

2. Conditional Probability Table (CPT)

CPT merepresentasikan probabilitas berdasarkan informasi prior. Secara matematis, sebuah conditional probability dapat ditulis dengan $\mathrm{P}(\mathrm{X}=\mathrm{X}$ $\mid \mathrm{P} 1=\mathrm{p} 1, \mathrm{P} 2=\mathrm{P} 2, \ldots, \mathrm{Pn}=\mathrm{pn})$ contoh probabilitas simpul X pada status $\mathrm{x}$ berdasarkan simpul orang tua $\mathrm{P} 1$ pada status $\mathrm{p} 1$, simpul orang tua $\mathrm{P} 2$ pada status p2, ..., dan simpul orang tua Pn pada status pn. Pada CPT terdapat status dari tiap variabel yang merupakan suatu nilai yang bisa diambil oleh node.

Menurut [3], Skenario use case Bayesian Netwok terlihat pada gambar 2 :

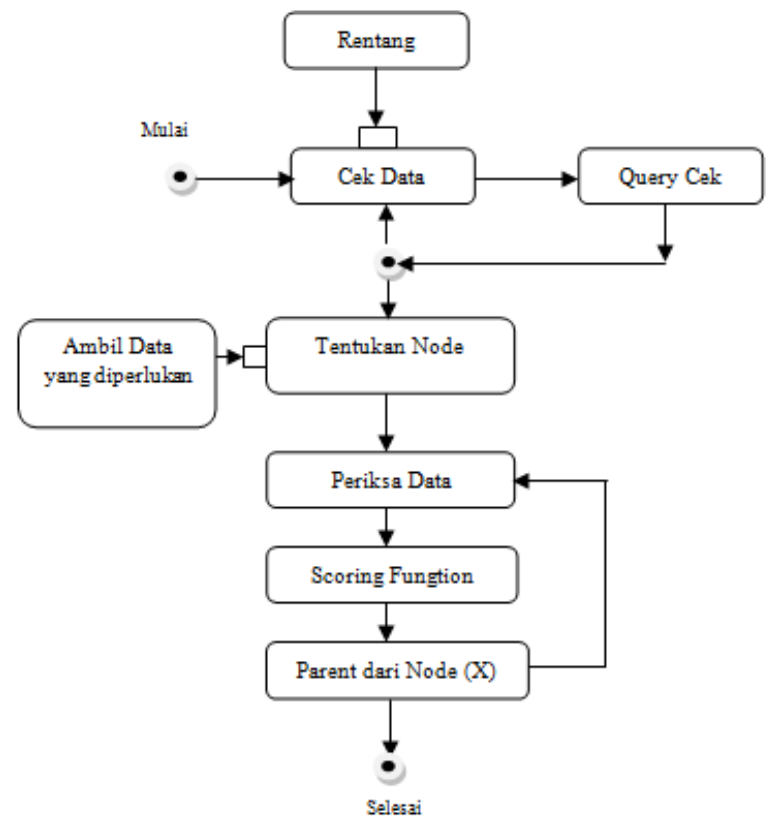

Gambar 2 Activity Diagram Membangun Struktur Bayesian Network

Menurut [5], Prediksi sendiri sebenarnya mempertimbangkan nilai yang belum terlihat pada masa akan datang berdasarkan pola-pola yang terjadi sebelumnya. Prediksi merupakan proses memprakirakan akan sesuatu dengan mengoreksi aksi sebelumnya, untuk meramalkan suatu kondisi dibutuhkan perhitungan yang tepat guna menjawab permasalahan tersebut. 
Menurut [6], Peramalan adalah proses untuk memperkirakan berapa kebutuhan dimasa yang akan datang yang meliputi kebutuhan dalam ukuran kwantitas, kwalitas, waktu dan lokasi yang dibutuhkan dalam rangka memenuhi permintaan barang ataupun jasa. Peramalan permintaan merupakan tingkat permintaan produk-produk yang diharapkan akan terealisasi untuk jangka waktu tertentu pada masa yang akan datang.

Menurut [7]. Analisis teknikal (technical analysis) adalah analisa untuk prediksi pergerakan harga saham di masa yang akan datang atas dasar data past perfomence atau pola pergerakan harga dan volume yang telah terjadi sebelumnya.

Menurut [8]. Teori Dow (The Dow Theory) Analisis teknikal merupakan analisis yang tua dan sangat terkenal dalam bagaiman cara menentukan tren mayor harga dibursa saham. Teori Dow menyebutkan bahwa mayoritas saham bergerak sejalan dengan bursa secara keseluruhan. Jika bursa saham bergerak naik, maka mayoritas saham akan bergerak naik juga. Dan sebaliknya jika bursa saham bergerak turun, maka kebanyakan saham akan bergerak turun.

Menurut [7]. Support dan Resistance adalah tingkat ketahanan harga dimana buying atau selling interest dapat mempertahankan agar harga tidak turun atau naik lebih besar lagi.

Menurut Budi Harsono [7]. Trendline atau garis tren merupakan kumpulan dari titik-titik yang membentuk suatu garis yang menandakan arah suatu pergerakan harga saham, yang secara umum terdapat 3 pola :

1. Up trendline (tren harga naik)

2. Down trend (tren harga turun)

3. Sideways trend (tren harga cenderung flat)

Trendline merupakan lekukan pada area supportresistance.

Pada analisis untuk pertimbangan pengambilan keputusan transaksi, dapat mengubah parameter time frame terhadap tren yang diamati, baik untuk keputusan eksekusi beli, jual, mempertahankan saham yang telah dimiliki, atau sekedar diam mengamati saja.

Dengan mengenali tren tersebut, khususnya pengenalan terhadap saham tertentu (fokus), maka akan sangat menentukan kesuksesan dalam melakukan investasi atau spekulasi yang dilakukan.

Keputusan transaksi tersebut, tetap harus memperhatikan support-resistance line yang telah dibahas sebelumnya dimana pada kecenderungan uptrend, harus mengingat bahwa kemungkinan terbesar harga maksimum akan sampai pada level resistance, dan pada kecenderungan down trend maka harus mengingat bahwa kemungkinan terbesar harga terendah akan sampai pada level support.

Artinya, jika konsisten menggunakan data trendline maka harus mengupayakan bahwa pembelian yang dilakukan sebisa mungkin di sekitar support level dan penjualan yang dilakukan harus di sekitar harga resistance level, sehingga akan diperoleh kemungkinan perolehan keuntungan tertinggi.
Menurut [9], Investasi pada hakikatnya merupakan penempatan sejumlah dana pada saat ini dengan harapan untuk memperoleh keuntungan di masa mendatang. Lebih jauh ekonomi asal Amerika Paul R. Krugman dan Obstfeld mengatakan bahwa bagian output yang digunakan oleh perusahaanperusahaan swasta guna menghasilkan output di masa mendatang disebut sebagai investasi.

Menurut [10], Bursa saham mengenal beberapa istilah berbahasa asing yang terkait dengan harga saham, seperti open, high, low, close, bid, dan ask. Berikut perjelasan istilah harga tersebut:

1. Open (pembukaan), harga yang terjadi pada transaksi pertama satu saham.

2. High (tertinggi), harga tertinggi transaksi yang tercapai pada satu saham.

3. Low (terendah), harga terendah transaksi yang tercapai pada satu saham

4. Close (penutupan), harga yang terjadi pada transaksi terakhir satu saham

5. Bid (minat beli), harga yang diminati pembeli untuk melakukan transaksi

6. Ask (minat jual), harga yang diminati penjual untuk melakukan transaksi.

Dalam investasi saham perusahaan yang sudah go-public, yaitu perusahaan tersebut dapat menjual sahamnya ke masyarakat umum. Di Indonesia istilah perusahaan go-public disebut sebagai perusahaan terbuka (Tbk.). Untuk dapat go-public, perusahaan perlu memenuhi semua persyaratan yang ditetapkan di antaranya :

1. Perseroan Terbatas (PT) yang beroperasi sekurangkurangnya 12 bulan.

2. Memiliki aktiva bersih berwujud sekurangkurangnya Rp 5.000.000.000 (lima miliar rupiah).

3. Laporan keuangan auditan tahun buku terakhir memperoleh opini wajar tanpa pengecualian dari akuntan publik yang terdaftar di Bapepam.

4. Menjual sekurang-kurangnya 50.000.000 (lima puluh juta) persen dari jumlah saham yang diterbitkan (mana yang lebih kecil).

5. Jumlah pemegang saham publik sekurangkurangnya 500 (lima ratus) pihak.

6. Pernyataan pendaftaran emisi telah dinyatakan efektif oleh Bapempam-LK.

\subsection{Permodelan Bayesian Network}

Model dari topologi Bayesian Network dapat dilihat pada gambar dibawah dimana terdapat variabelvariabel yang saling berhubungan yang ditandai dengan tanda panah dengan asumsi sebagai berikut :

1. Untuk menghasilkan prediksi portofolio yang optimal dalam menentukan sinyal beli/jual dari indikator analisis teknikal modern Sample Moving Average (SMA), Relative Strength Index (RSI) dan Bollinger Band (BB). SMA, RSI dan BB merupakan indikator-indikator yang tugasnya menentukan sinyal beli dan sinyal jual. Karena data yang akan digunakan oleh ketiga indikator tersebut adalah data harga saham penutup. 
2. Data BB dan RSI dapat menggunakan SMA sebagai indikator bantu yang diasumsikan bahwa ada hubungan antara kedua indikator teknikal sehingga dapat ditarik tanda panah seperti gambar dibawah ini.

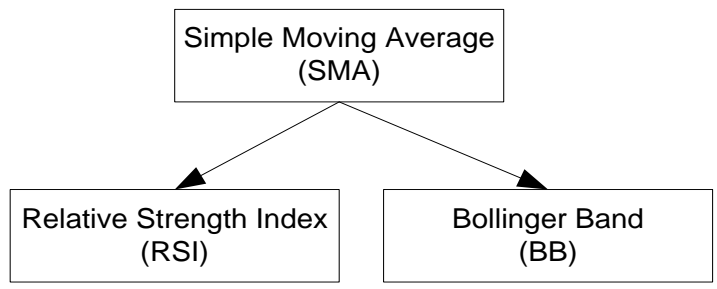

Gambar 3 Pembentukan Topologi Bayesian Network

3. Ketiga indikator teknikal SMA, RSI dan BB memiliki tujuan yang sama yaitu mengidentifikasikan adanya sinyal jual/beli. Dengan asumsi tersebut meyakinkan adanya hubungan sinyal jual/beli (rekomendasi) terhadap SMA, RSI dan BB, sehingga dapat ditarik tanda panah sebagai berikut :

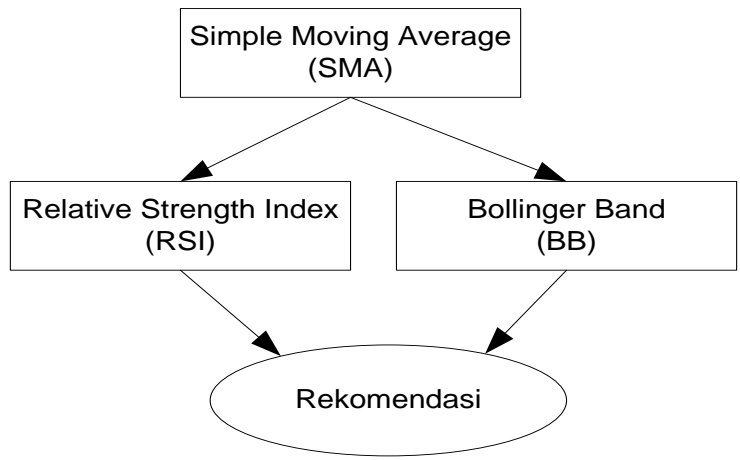

\section{Gambar 4 Model Akhir Dari Topologi Bayesian}

Network

Setelah langkah membuat topologi Bayesian Network selesai, langkah selanjutnya yang harus dilakukan adalah mengestimasi nilai peluang yang dihubungkan dengan tiap node. Sebelum mengestimasi peluang pada prediksi portofolio saham yang optimal ada baiknya mencari peluang dan mengasumsikan beberapa hal seperti :

1. Dalam melakukan analisa keputusan jual atau beli, seorang investor memerlukan suatu teknik. Salah satu teknik menentukan kapan jual dan kapan beli dalam manajemen protofolio menggunakan analisis teknikal yang dibagi menjadi dua bagian yaitu analisis teknikal klasik dan analisis teknikal modern. Indikator yang digunakan adalah SMA, RSI dan BB. Indikator tersebut digunakan karena data input yang diperlukan dari ketiga indikator sama yaitu penutup dan periode tertentu.

2. Ketiga indikator tersebut memiliki hubungan. SMA menjadi indikator bantu dalam RSI dan BB.
Gambar dibawah ini menjelaskan tentang model dari Bayesian Network yang telah di desain terlebih dahulu dengan beberapa asumsi.

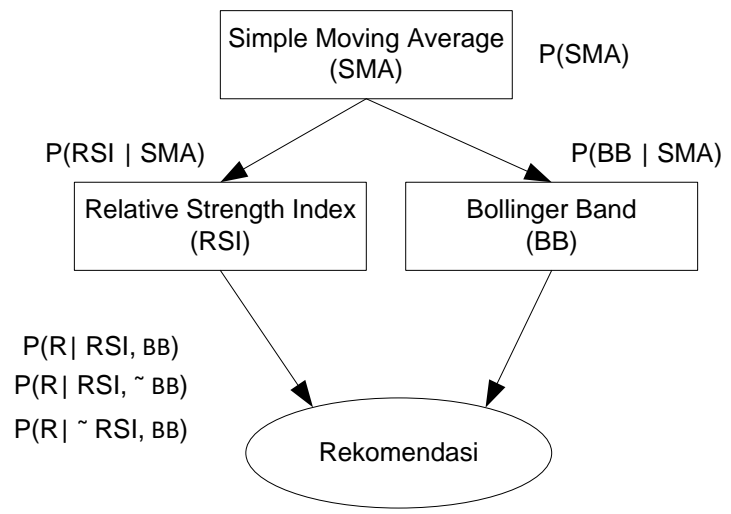

Gambar 5 Model Bayesian Network dan Estimasi Peluang

Gambar di atas menjelaskan struktur Network Bayesian dan estimasi peluang. Setelah menghitung Peluang SMA atau P(SMA), dapat menghitung Peluang RSI terhadap SMA atau P(RSI|SMA), Peluang BB terhadap SMA atau $\mathrm{P}(\mathrm{BB} \mid \mathrm{SMA})$, dari perhitungan tersebut maka dapat direkomendasikan beberapa peluang yaitu Peluang Rekomendasi terhadap RSI dan BB atau P(R $\mid$ RSI, BB).

Setelah selesai pembuatan model dari Bayesian Network, tahap selanjutnya adalah menghitung peluang dengan menggunakan teorema Bayes. Untuk mendapatkan nilai peluang diperlukan perhitungan frekuensi berdasarkan data saham. Tentukan nilai peluang.

$$
\text { Peluang }=\frac{\text { Frekuensi }}{\text { Periode }}
$$

Dari penjelasan model Bayesian Network, maka ditentukan rumus peluang untuk rekomendasi prediksi portofolio yang sesuai dengan teorema Bayes yang menjadi landasan utama dari model Bayesian Network .Rekomendasi adalah hasil akhir atau keputusan yang diambil tiap indikator. Tiap indikator memiliki tujuan yang sama yaitu mengambil keputusan sinyal jual atau sinyal beli. Beberapa alat bantu indikator analisis teknikal modern SMA, RSI dan BB. Dari asumsi tersebut maka rekomendasi memiliki tiga orang tua yang nilai peluangnya adalah $\mathrm{P}(\mathrm{R} \mid \mathrm{RSI}, \mathrm{BB})$ diperoleh dengan menjumlahkan nilai peluang RSI dan BB dibagi 2. Adapun rumus tersebut adalah :

$$
R=\frac{P(R S I)+P(B B)}{2}
$$

Untuk tahap selanjutnya adalah menetapkan atau menentukan hasil yang diperoleh. Rekomendasi yang diperoleh terdiri dari dua keadaan yaitu rekomendasi jual dan rekomendasi beli. Teori matematika untuk peluang dari ruang pencuplikan dari sekumpulan bilangan disebut pembobot (weights), dengan nilai antara 0 sampai 1, sebagai cara mengevaluasi 
kebolehjadian (likehood) munculnya suatu peristiwa dari eksperimen statistik. Setiap titik dalam ruang pencuplikan diboboti sedemikian rupa sehingga jumlah keseluruhan dari pembobot menjadi 1. Dengan demikian kejadian dengan kemungkinan tinggi diberi bobot mendekati 1 dan kejadian yang lebih mustahil diberi bobot mendekati 0 .

Begitu juga dalam merekomendasikan sinyal jual dan beli, nilai peluang yang mendekati 1 yang menjadi rekomendasi. Jika $\mathrm{A}^{\mathrm{c}}$ adalah kejadian komplementer dari kejadi A, maka : $P\left(A^{\prime}\right)=1-P(A)$.

Untuk rekomendasi prediksi portofolio, jika sinyal jual melalui perhitungan di atas, maka untuk menentukan sinyal beli sangat mudah dengan mengurangi nilai 1 dengan nilai dari sinyal jual, begitu juga sebaliknya.

Berikut ini adalah gambar diagram hirarki yang menjelaskan struktur sistem yang akan dirancang.

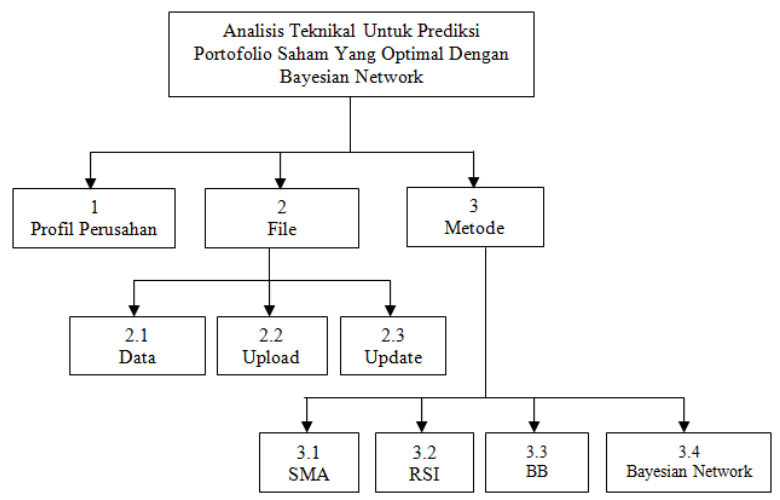

Gambar 6 Diagram Hirarki

\subsection{Hasil}

Form menu utama adalah form yang pertama kali aktif ketika sistem running. Pada form menu utama terdapat 3 (tiga) pilihan yagn dapat diakses oleh user. Adapun bentuk form menu utama dapat dilihat pada gambar berikut

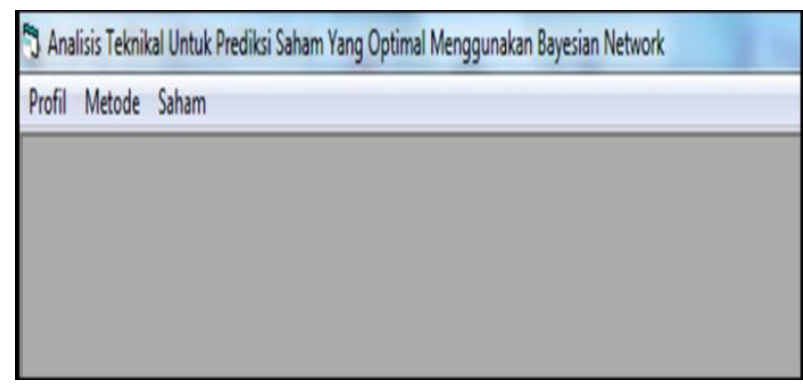

Gambar 7 Form Menu Utama

Seperti pada gambar di atas terdapat 3 (tiga) menu yaitu profil untuk melihat profil suatu perusahaan, metode untuk menganalisis dari beberapa metode yang digunakan SMA, RSI, BB, Bayesian Network dan saham untuk melihat data-data saham.

Form profil perusahaan akan terlihat pada gambar di bawah ini

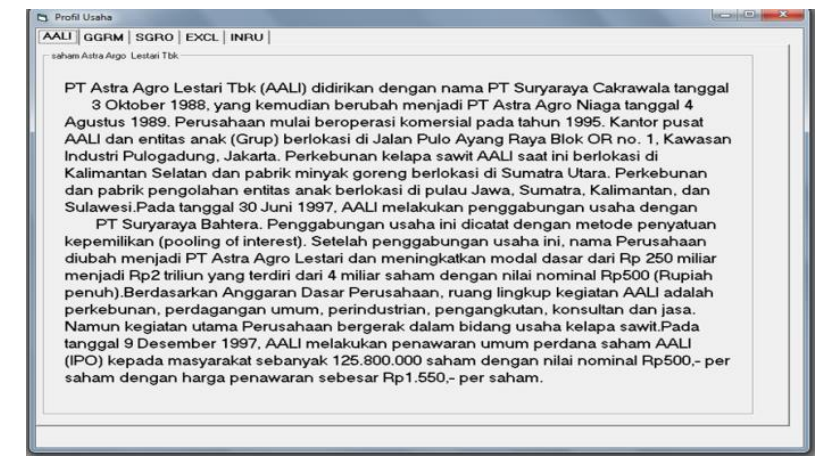

\section{Gambar 8 Form Profil}

Gambar form profil diatas menjelaskan beberapa pilihan perusahaan yang akan dianalisis. Jika user mengklik atau memilih salah satu dari kode-kode perusahaan tersebut seperti AALI, SGRO, GGRM, EXCL, INRU maka tampil profil dari perusahaan tersebut.

Gambar dibawah ini adalah form metode dari analisis teknikal saham Adapun bentuk form metode analisis dapat dilihat pada gambar berikut

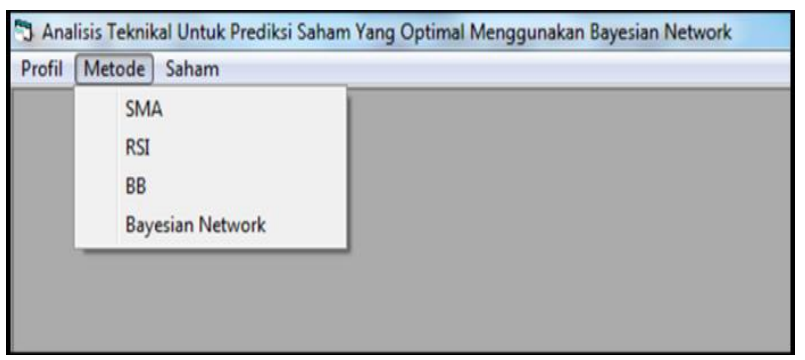

Gambar 9 Form Metode Analisis

Pada form metode analisis diatas terdapat beberapa pilihan untuk dianalisa seperti SMA, RSI, BB dan Bayesian Network. Metode SMA berfungsi untuk melihat pergerakan saham dan mendapatkan rekomendasi sesuai dengan keputusan SMA. RSI berfungsi untuk melihat pergerakan saham dan mendapatkan rekomendasi sesuai dengan keputusan RSI, BB berfungsi untuk melihat pergerakan saham dengan metode $\mathrm{BB}$ akan mendapatkan rekomendasi sesuai dengan keputusan BB. Dengan Bayesian Network dapat menentukan peluang kombinasi dari peluang RSI dan BB.

Gambar di bawah ini adalah form saham yang akan dianalisis. Adapun bentuk form metode analisis dapat dilihat pada gambar berikut 


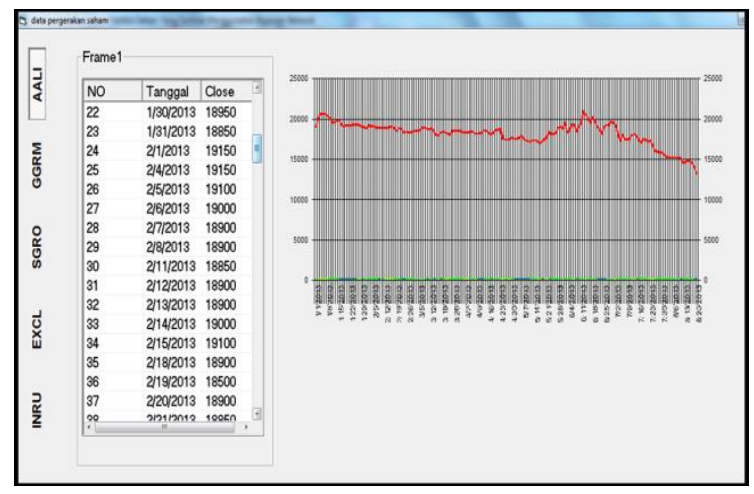

Gambar 10 Form Saham

Pada form saham di atas terdapat beberapa pilihan data saham yang telah diinputkan seperti AALI, SGRO, INRU, EXCL, GGRM. Input data saham penulis ambil dari www.finance@yahoo.com, dari mulai tanggal 1 Januari sampai dengan 20 Agustus 2013, data yang diambil hanya date dan close sebagai bahan analisis.

Gambar dibawah ini adalah formmetode Sample Moving Average (SMA). Adapun bentuk form metode SMA dapat dilihat pada gambar berikut

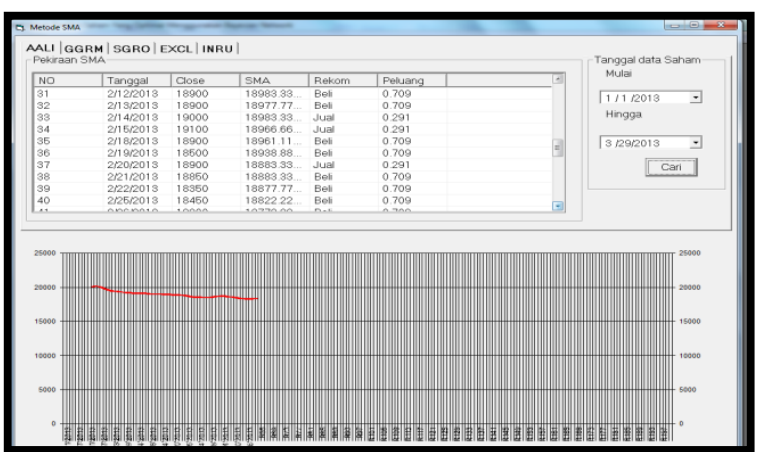

Gambar 11 Form Metode Sample Moving Average (SMA)

Pada form metode SMA di atas terdapat beberapa pilihan data saham yang telah di inputkan seperti AALI, SGRO, INRU, EXCL, GGRM. Pada form terdapat pilihan tanggal, user dapat memilih tanggal awal dan tanggal akhir sesuai dengan keinginan user, dengan menekan tombol cari maka tampil data-data yang diinginkan dan menampilkan peluangnya berdasarkan metode SMA dan dapat melihat grafik dari pergerakan saham.

Gambar dibawah ini adalah formmetode Relative Strength Index (RSI). Adapun bentuk form metode RSI dapat dilihat pada gambar berikut

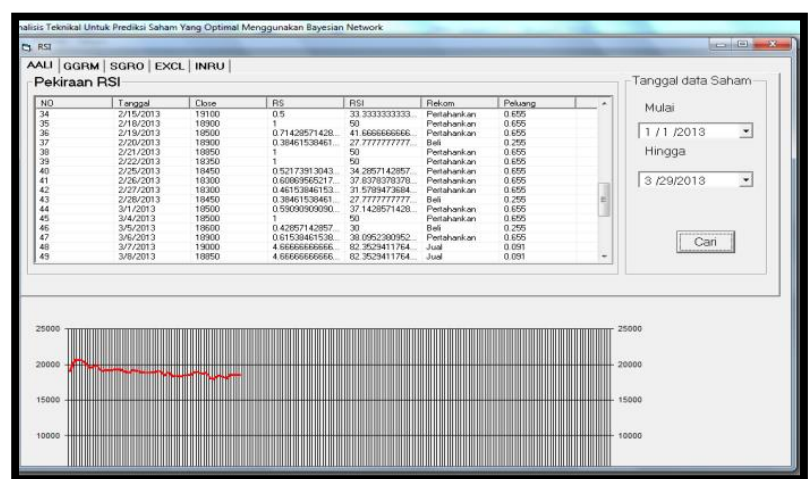

Gambar 12 Form Metode Relative Strength Index (RSI)

Pada form metode RSI terdapat beberapa pilihan data saham yang telah di inputkan seperti AALI, SGRO, INRU, EXCL, GGRM. Pada form terdapat pilihan tanggal, user dapat memilih tanggal awal dan tanggal akhir sesuai dengan keinginan user, dengan menekan tombol cari maka tampil data-data yang diinginkan dan menampilkan peluangnya berdasarkan metode RSI dan dapat melihat grafik dari pergerakan saham.

Gambar dibawah ini adalah formmetode Bollinger Bands (BB). Adapun bentuk form metode BB dapat dilihat pada gambar berikut

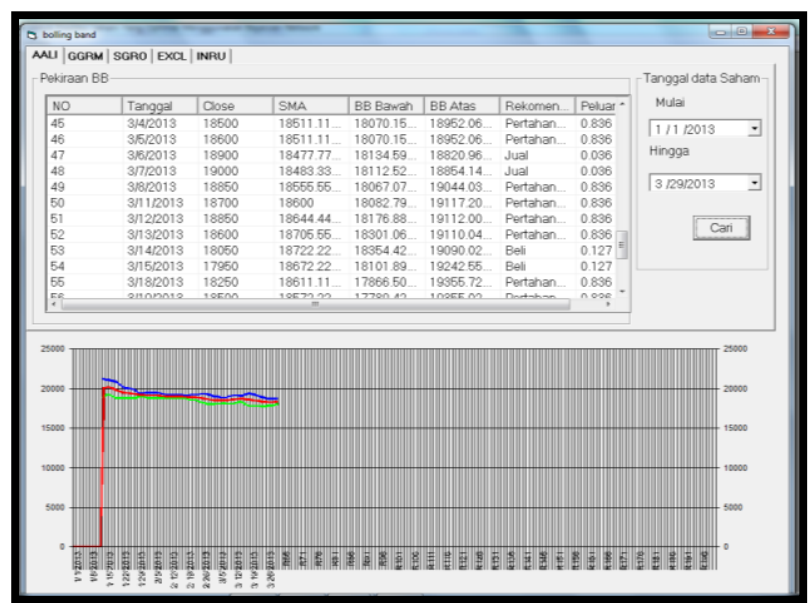

Gambar 13 Form Metode Bollinger Bands (BB)

Pada form metode BB di atas terdapat beberapa pilihan data saham yang telah di inputkan seperti AALI, SGRO, INRU, EXCL, GGRM. Pada form terdapat pilihan tanggal, user dapat memilih tanggal awal dan tanggal akhir sesuai dengan keinginan user, dengan menekan tombol cari maka tampil data-data yang diinginkan dan menampilkan peluangnya berdasarkan metode BB dan dapat melihat grafik dari pergerakan saham.

Gambar dibawah ini adalah formmetode Bayesian Network (BN).Form Bayesian Network dapat dilihat pada gambar berikut 


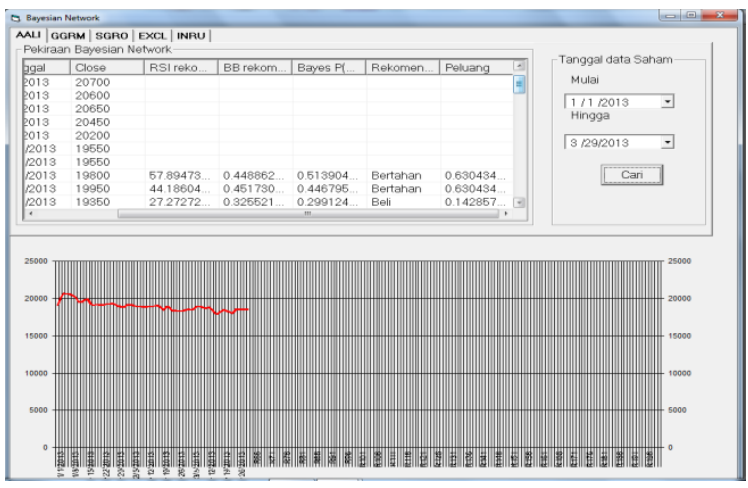

Gambar 14 Form Metode Bayesian Network (BN)

Pada form metode Bayesian Network di atas terdapat beberapa pilihan data saham yang telah diinputkan seperti AALI, SGRO, INRU, EXCL, GGRM. Pada form terdapat pilihan tanggal, user dapat memilih tanggal awal dan tanggal akhir sesuai dengan keinginan user, dengan menekan tombol cari maka tampil data-data yang diinginkan dan menampilkan peluangnya berdasarkan kombinasi antara metode RSI dan metode BB dan dapat melihat grafik dari pergerakan saham. Dengan metode Bayesian Network para investor mudah dalam menentukan pilihan untuk jual dan beli saham yang lebih optimal.

\subsection{Pengujian}

Untuk pengujian pada analisis teknikal saham penulis mencoba dengan 2 cara yaitu dengan menggunakan Microsoft Visual Basic 6.0 dan Microsoft Excel. Dimana dari kedua cara tersebut mendapatkan menghasilkan data yang sama setelah diuji.

Untuk analisis pengujian pergerakan saham dan rekomendasi jual atau beli menggunakan metode Simple Moving Average (SMA) pada gambar diatas, jika harga close lebih kecil dengan SMA maka direkomendasikan agar beli saham, dan jika harga close lebih besar dari harga SMA maka direkomendasikan untuk jual saham, dari hasil analisa dengan membandingkan histori saham dengan prediksi yang direkomendasikan masih banyak prediksi yang tidak tepat, karena prediksi hanya memiliki dua rekomendasi jual dan beli, akan mengakibatkan tidak didapatkan kapan waktu yang paling tepat untuk membeli saham dan kapan waktu yang paling tepat untuk menjual saham.

Tabel 1 Pengujian Simple Moving Average (SMA)

\begin{tabular}{|r|r|r|r|r|}
\hline No & Tanggal & Close & $\begin{array}{c}\text { Perkiraan } \\
\text { Harga SMA }\end{array}$ & Rekomendasi \\
\hline 1 & $1 / 23 / 2013$ & 19250 & 19427.77778 & Beli \\
\hline 2 & $2 / 11 / 2013$ & 18850 & 19000 & Beli \\
\hline 3 & $3 / 4 / 2013$ & 18500 & 18511.11111 & Beli \\
\hline 4 & $2 / 14 / 2013$ & 19000 & 18983.33333 & Jual \\
\hline 5 & $3 / 11 / 2013$ & 18700 & 18600 & Jual \\
\hline
\end{tabular}

Untuk analisis pengujian pergerakan saham dan rekomendasi jual, beli dan pertahankan menggunakan metode Relative Strength Index (RSI) pada gambar 14 diatas, jika harga RSI dibawah 30 maka direkomendasikan agar beli saham, jika harga RSI diatas 70 maka direkomendasikan agar jual saham, dan jika harga RSI antara 30 sampai dengan 70 maka direkomendasikan agar saham dipertahankan. Dari hasil analisis yang dilakukan dengan membandingkan histori saham dengan prediksi yang direkomendasikan masih lebih bagus dari SMA, karena prediksi memiliki tiga rekomendasi jual, beli pertahankan, pada RSI investor dapatkan mempertahankan kapan waktu yang paling tepat untuk beli saham, jual saham dan menpertahankan saham.

Tabel 2 Pengujian Relative Strength Index (RSI)

\begin{tabular}{|c|r|r|r|l|}
\hline No & \multicolumn{1}{c|}{ Tanggal } & Close & \multicolumn{1}{c|}{ RSI } & Rekomendasi \\
\hline 1 & $2 / 28 / 2013$ & 18450 & 27.77777778 & Beli \\
\hline 2 & $3 / 1 / 2013$ & 18500 & 37.14285714 & Pertahankan \\
\hline 3 & $3 / 5 / 2013$ & 18600 & 30 & Beli \\
\hline 4 & $3 / 6 / 2013$ & 18900 & 38.0952381 & Pertahankan \\
\hline 5 & $3 / 7 / 2013$ & 19000 & 82.35294118 & Jual \\
\hline
\end{tabular}

Untuk analisis pengujian pergerakan saham dan rekomendasi jual, beli dan pertahankan menggunakan metode Bollinger Bands (BB) pada gambar 15 di atas, akan lebih baik lagi bagi investor, karena BB merupakan kombinasi dari Moving Average dan standar deviasi dan mempunyai BB bawah dan BB atas, yang dapat membuat seorang investor menahan diri untuk dapat mempertahankan kapan beli, jual dan pertahankan harga saham, dengan analisis yang dilakukan dengan membandingkan histori saham dan pergerakan antara RSI dan BB.

Tabel 3 Pengujian Bollinger Bands (BB)

\begin{tabular}{|c|r|r|r|r|l|}
\hline No & $\begin{array}{c}\text { Tangg } \\
\text { al }\end{array}$ & $\begin{array}{c}\text { Clos } \\
\text { e }\end{array}$ & $\begin{array}{c}\text { BB } \\
\text { Bawah }\end{array}$ & BB Atas & $\begin{array}{l}\text { Rekomen } \\
\text { dasi }\end{array}$ \\
\hline 1 & $2 / 22 / 2$ & 183 & 18553.3 & 19202.24 & \\
& 013 & 50 & 1241 & 315 & Beli \\
\hline 2 & $2 / 25 / 2$ & 184 & 18342.3 & 19302.09 & Pertahanka \\
& 013 & 50 & 4955 & 489 & n \\
\hline 3 & $3 / 5 / 20$ & 186 & 18070.1 & 18952.06 & Pertahanka \\
& 13 & 00 & 5256 & 966 & n \\
\hline 4 & $3 / 6 / 20$ & 189 & 18134.5 & 18820.96 & \\
& 13 & 00 & 9011 & 545 & Jual \\
\hline 5 & $3 / 14 / 2$ & 180 & 18354.4 & 19090.02 & \\
& 013 & 50 & 2095 & 35 & Beli \\
\hline
\end{tabular}

Untuk analisis pengujian pergerakan saham dan rekomendasi jual, beli dan pertahankan menggunakan metode Bayesian Network (BN) pada gambar 16 di atas Bayesian Network (BN) menggunakan peluang Relative Strength Index dan Bollinger Bands, peluang BB jual yang kondisi RSI jual, peluang BB beli yang kondisi RSI beli, peluang BB pertahankan yang kondisi RSI pertahankan, sehingga menghasilkan rekomendasi hasil yang baik. Bayesian Network bekerja lebih baik untuk pengambilan keputusan bagi seorang investor.

Tabel 4 Pengujian Bayesian Network (BN)

\begin{tabular}{|c|c|c|r|r|}
\hline No & Tanggal & Close & Rekomendasi & Peluang \\
\hline 1 & $2 / 19 / 2013$ & 18850 & Beli & 0.142857143 \\
\hline 2 & $2 / 20 / 2013$ & 19900 & Pertahankan & 0.630434783 \\
\hline 3 & $3 / 6 / 2013$ & 18900 & Pertahankan & 0.630434783 \\
\hline 4 & $3 / 7 / 2013$ & 19000 & Jual & 0,5 \\
\hline 5 & $3 / 8 / 2013$ & 18850 & Jual & 0,5 \\
\hline
\end{tabular}




\section{Kesimpulan}

Dalam implementasi dan pengujian sistem pada analisis teknikal yang telah dilakukan dengan menggunakan metode Bayesian Network terdapat beberapa hal yang disimpulkan dari penelitian ini antara lain sebagai berikut :

1. Sistem yang dibangun untuk prediksi portofolio saham, dapat membantu para investor dalam pengambilan keputusan dan menjadi solusi yang tepat dalam prediksi saham.

2. Bayesian Network dapat membantu dalam mengkombinasikan antara metode Relative Strength Index (RSI) dan metode Bollinger Bands (BB), sehingga tingkat kepercayaan lebih besar terhadap sistem yang dibangun.

3. Dalam analisis teknikal metode Relative Strength Index (RSI) dan metode Bollinger Bands (BB) dapat merekomendasikan dengan baik, untuk peluang kapan saham jual dan kapan saham harus beli.

\section{Penutup}

Adapun selama pengujian sistem terdapat kelemahan-kelamahan, sehingga dibutuhkan saran yang dapat dikembangkan untuk kelanjutan sistem ini. Saran yang penulis harapaan dari penelitian ini adalah :

1. Diharapkan sistem ini dapat dikembangkan dengan menambahkan metode-metode teknikal lainnya sehingga mendapatkan rekomendasi yang memuaskan.

2. Sistem saham dengan analisis teknikal dapat menjadi lebih bagus dengan menggabungkan metode fundamental agar para investor dapat mengetahui pergerakan saham sekaligus prosfek kedepan perusahaan tersebut, sehingga investor mamapu memperhitungkan dalam waktu jangka panjang.

3. Diharapkan sistem ini mampu terhubung langsung dengan database sebenarnya pada saham Bursa Efek Jakarta (BIJ), agar sistem ini dapat digunakan oleh banyak user dan data akan selalu up date.

\section{DAFTAR PUSTAKA}

[1] Mohammad Safrodin', Surya Sumpeno ${ }^{2}$, Moch. Hariadi $^{3}$, Autonomous Leveling Sentence Composer Berbasis Causal Bayesian Network Untuk Intelligent Tutoring System, Surabaya, Jurnal Elektro. Teknology Industri ITS, 2010

[2] Variq ${ }^{1}$, Surya Sumpeno ${ }^{2}$, Moch, Hariadi3, Purnama ${ }^{4}$, Sistem Tutor Cerdas Menggunakan Metode Bayesian Network. Jurnal Bidang Studi Tekni, Surabaya, Komputer dan Telematika Teknik Elektro, 2010

[3] Sayuti Rahman, Ihsan Lubis, Husni Lubis, Penanganan Mising Value dengan Metode Bound and Collapse Pada Struktur Bayesian Network, Medan, Seminar Nasional Teknologi Informasi dan Komunikasi (SNASTIKOM), 2012
[4] Oktavia Ari Marlita ${ }^{1}$, Adiwijaya ${ }^{2}$, Angelina Prima Kurniati $^{3}$, Anomaly Detection Pada Intrusion Detection System (IDS) Menggunakan Metode Bayesian Network, Vol. 17. No. 1, Jurnal Penelitian dan Pengembangan Telekomunikasi ,2012

[5] Iriansyah BM Sangadji, Prediksi Perilaku Pola Pengunjung Terhadap Transaksi Pada Toko Buku Gramedia Menggunakan Jaringan Syaraf Tiruan Metode Back Propagation, Jurnal, 2009

[6] Fachrudin Pakaja, Agus Naba dan Purwanto, Peramalan Penjualan Mobil Menggunakan Jaringan Syaraf Tiruan Dan Certainty Factor, Vol. 6. No. 1, Jurnal EECCIS, 2012.

[7] Budi Harsono S, Efektif Bermain Saham, Jakarta, Penerbit PT. Elex Media Komputindo, 2013

[8] Christine Suryadi, Probabilitas dan Statistika Teorema Bayes, Institut Teknologi Bandung, 2003

[9] Irham Fahmi, Pengantar Pasar Modal, Bandung, Penerbit Alfabeta Cv , 2012

[10] L. Thain Hin, Panduan Berinvestsi Saham, Jakarta, Penerbit PT. Elex Media Komputindo, 2008 